\title{
STUDI DAMPAK PENGEMBANGAN PARIWISATA TERHADAP PERKEMBANGAN SOSIAL EKONOMI MASYARAKAT DI SEKITAR DESTINASI WISATA
}

\section{STUDY ON THE IMPACT OF TOURISM DEVELOPMENT ON SOCIAL ECONOMIC DEVELOPMENT IN COMMUNITY DESTINATIONS}

\author{
Agus Putra A. Samad ${ }^{1 *}$, Baihaqi², Cut Mulyani ${ }^{3}$ \\ 1Prodi Akuakultur Fakultas Pertanian Universitas Samudra, Aceh \\ 2Prodi Bahasa Inggris Fakultas Keguruan dan Ilmu Pendidikan Universitas Samudra, Aceh \\ 3Prodi Agroteknologi Fakultas Pertanian Universitas Samudra, Aceh \\ e-mail: agusputra@unsam.ac.id
}

\begin{abstract}
Abstrak: Tujuan utama penelitian ini adalah untuk meneliti secara komprehensif tentang pengaruh keberadaan objek wisata Hutan Mangrove dan Taman Hutan Kota terhadap peningkatan kesejahteraan masyarakat dan pedagang yang berada disekitar destinasi wisata serta menganalisa dampak yang ditimbulkan dari keberadaan objek wisata Taman Hutan Kota dan Hutan Mangrove terhadap peningkatan kesejahteraan masyarakat. Sedangkan output yang ingin dicapai adalah diperolehnya data hasil penelitian secara mendetail dan lengkap tentang pengaruh keberadaan objek wisata tersebut. Kajian ini dilakukan menggunakan metode survey dan observasi lapangan. Pengumpulan data sosial ekonomi tempat wisata dikumpulkan melalui metode wawancara terhadap responden yang dipilih secara purposive sampling. Pengolahan dan analisis data hasil penelitian menggunakan metode statistik deskripitif. Hasil penelitian menunjukkan bahwa secara umum masyarakat sekitar kawasan wisata sangat mendukung keberadaan tempat-tempat wisata tersebut. Demikian pula dengan tingkat dukungan masyarakat terhadap hadirnya tempat wisata taman hutan kota juga sangatlah tinggi.
\end{abstract}

Kata kunci : hutan mangrove, taman hutan kota, Langsa, wisata

\begin{abstract}
The main objective of this study is to comprehensively examine the influence of the existence of Mangrove Forest and Urban Forest Park attractions on improving the welfare of the community and traders, who are around the tourist destination and also analyze the impact arising from the existence of the City Forest and Mangrove Forest tourist attraction to the increase of public welfare. While, the output is to obtain the detailed and completed research data on the influence of the existence of these attractions. This study was conducted using survey methods and field observations. Collection of socioeconomic data on tourist attractions was collected through interviews with respondents selected by purposive sampling. Processing and analyzing of research data using descriptive statistical methods. The results showed that in general the community around the tourist area strongly supports the existence of these tourist attractions. Likewise, the level of community support for the presence of urban forest park attractions is also very high.
\end{abstract}

Keywords: mangrove forest, urban forest park, Langsa, tourism 


\section{PENDAHULUAN}

Sektor pariwisata merupakan sektor yang potensial untuk dikembangkan sebagai salah satu sumber pendapatan daerah. Dalam usaha memperbesar pendapatan asli daerah, maka program pengembangan dan pendayagunaan sumber daya dan potensi wisata daerah diharapkan dapat memberikan sumbangan bagi pembangunan ekonomi. Secara luas wisata dipandang sebagai kegiatan yang mempunyai multidimensi dari rangkaian suatu proses pembangunan (Ayob, dkk, 2009; Bahar, 2004)

Hal tersebut sejalan dengan UndangUndang Nomor 10 tahun 2009 Tentang Kepariwisataan yang menyatakan bahwa Penyelenggaraan Kepariwisataan ditujukan untuk meningkatkan pendapatan nasional dalam rangka meningkatkan kesejahteraan dan kemakmuran rakyat, memperluas, memeratakan kesempatan berusaha dan lapangan kerja, mendorong pembangunan daerah, memperkenalkan dan mendayagunakan daya tarik wisata di Indonesia dan daerah serta memupuk rasa cinta tanah air dan mempererat persahabatan antar daerah (DKP, 2007). Perkembangan pariwisata juga mendorong dan mempercepat pertumbuhan ekonomi. Kegiatan pariwisata menciptakan permintaan, baik konsumsi maupun investasi yang pada gilirannya akan menimbulkan kegiatan produksi barang dan jasa Cohen dalam Pitana dan Diarta (2009).

Kota Langsa dengan keterbatasan sumber daya alam memiliki beberapa destinasi wisata yang dapat dikembangkan dan dikelola menjadi salah satu sumber pendapatan asli daerah diantaranya Hutan Kota di Gampong Paya Bujok Seuleumak dan Hutan Mangrove di gampong Kuala Langsa. Kedua destinasi wisata saat ini telah ikut berkontribusi bagi peningkatan ekonomi masyarakat sekitar serta berdampak terhadap penerimaan retribusi bagi daerah.

Berdasarkan hal tersebut diatas, peneliti tertarik untuk melakukan penelitian sekaligus menganalisa pengaruh keberadaan objek wisata Hutan Kota dan Hutan Mangrove bagi peningkatan kesejahteraan masyarakat dan pedagang di Kota Langsa.

\section{METODOLOGI}

Adapun metode penelitian yang digunakan dalam penelitian ini adalah deskriptif kualitatif dengan teknik pengumpulan datanya melalui observasi dan wawancara terstruktur. Metode ini dipergunakan untuk menemukan gambaran dan persepsi masyarakat tentang dampak keberadaan kedua objek wisata bagi peningkatan kesejahteraan masyarakat sekitar objek wisata.
Sejumlah teknik pengumpulan data kualitatif yang umumnya digunakan dalam penelitian kualitatif antara lain : teknik (1) survei, (2) partisipasi, (3) observasi, (4) interview, (5) catatan lapangan dan memo analitik, (6) elisitasi dokumen, (7) pengalaman personal, dan (8) partisipasi dalam kaji tindak. Berbagai teknik pengumpulan data itu sebenarnya hanya merupakan "metodological trade" yang bisa dimodifikasi sesuai dengan kepentingan peneliti (Denzin dan Lincoln, 1994).

Terkait dengan teknik observasi, Edwards dan Talbott (1994) mencatat: all good practitioner research studies start with observations. Observasi demikian bisa dihubungkan dengan upaya: merumuskan masalah, membandingkan masalah (yang dirumuskan dengan kenyataan di lapangan), pemahaman secara detil permasalahan (guna menemukan pertanyaan) yang akan dituangkan dalam kuesioner, ataupun untuk menemukan strategi pengambilan data dan bentuk perolehan pemahaman yang dianggap paling tepat.

Metode observasi dilakukan untuk merekam gambaran suatu fakta sesuai dengan perbedaan. Oleh sebab itu, observasi dilakukan secara berurutan sesuai dengan karakteristik domain yang mau direkam (Adler dan Adler, 1994).

Metode interview merupakan salah satu cara pengambilan data yang dilakukan melalui kegiatan komunikasi lisan dalam bentuk terstruktur. Interview yang terstruktur merupakan bentuk interview yang sudah diarahkan oleh sejumlah pertanyaan secara ketat.

Nilai Keaslian (Originality) hutan mangrove dihitung dengan menggunkan rumus Or $=\{1-(\mathrm{Am} / \mathrm{An})\} \times 100 \%$; dimana Or = Nilai keaslian; $\mathrm{Am}=$ luasan ekosistem binaan/buatan; An = luasan ekosistem yang dinilai (Dirjen Pesisir dan Pulau- Pulau Kecil, 2002). Dengan menggunakan rumus tersebut, maka Nilai Keaslian (Originality) hutan mangrove di Langsa adalah sebagai berikut: Or $=\{1-(300 / 1.000\} \times 100 \%=70 \%$. Berdasarkan skala Nilai Keaslian ( $>80 \%=$ sangat asli; 60-79 \% = lebih dari asli; 40-59\% = asli; 20-39\%= kurang asli dan $<20 \%=$ tidak asli).

Untuk mendapatkan Nilai Keindahan Alam (Natural Beauty) hutan mangrove dilakukan dengan menggunakan daftar pertanyaan (kuisioner) terhadap pengunjung. Jumlah responden yang dipilih adalah sebanyak 50 orang. Dari seluruh responden tersebut yang menyatakan bahwa hutan mangrove indah adalah sebanyak 37 orang. Dengan 
menggunakan rumus : $\mathrm{Ka}=($ Ers/Ero $) \times 100$ $\%$, dimana $: \mathrm{Ka}=$ nilai keindahan alam dalam $\%$; Ers $=$ jumlah responden yang sepakat mengatakan indah, dan Ero = jumlah seluruh responden (Dirjen Pesisir dan Pulau-Pulau Kecil, 2002).

Untuk mendapatkan Nilai Keindahan Alam (Natural Beauty) hutan mangrove dilakukan dengan menggunakan daftar pertanyaan (kuisioner) terhadap pengunjung. Jumlah responden yang dipilih adalah sebanyak 50 orang. Dari seluruh responden tersebut yang menyatakan bahwa hutan mangrove indah adalah sebanyak 37 orang. Dengan menggunakan rumus : Ka $=($ Ers/Ero) $\times 100$ $\%$, dimana $: \mathrm{Ka}=$ nilai keindahan alam dalam $\%$; Ers = jumlah responden yang sepakat mengatakan indah, dan Ero = jumlah seluruh responden (Dirjen Pesisir dan Pulau-Pulau Kecil, 2002)

Adapun prosedur penelitian penelitian secara lengkap menggunakan tiga alur kegiatan secara bersamaan yaitu; 1) Tabulasi Data, 2) Penyajian Data dan 3) Penyimpulan Data.

\section{HASIL}

Partisipasi masyarakat yang berada disekitar kawasan wisata Hutan Mangrove mempunyai peranan yang tidak kalah pentingnya bagi kelestarian ekosistem mangrove. Partisipasi tersebut telah dilaksanakan secara individual maupun kelompok masyarakat. Hal ini sesuai dengan Undang-Undang Nomor 23 Tahun 1997 tentang Pengelolaan Lingkungan Hidup (UU No. 23/1997) Pasal 6 ayat (1) yang berbunyi "setiap orang mempunyai hak dan kewajiban untuk berperan serta dalam rangka pengelolaan lingkungan hidup". Dalam penjelasannya ditegaskan bahwa hak dan kewajiban setiap orang sebagai anggota masyarakat untuk berperan serta dalam kegiatan pengelolaan lingkungan hidup mencakup baik terhadap perencanaan maupun tahap-tahap perencanaan dan penilaian.

Tabel 3.1. Dukungan masyarakat di sekitar kawasan wisata Hutan Mangrove

\begin{tabular}{|c|c|c|c|c|c|c|}
\hline No & Pertanyaan & Sangat & Setuju & Ragu & Kurang & Tidak \\
\hline 1 & Masyarakat perlu mendukung & 27 & 73 & & & \\
\hline 2 & $\begin{array}{l}\text { Masyarakat perlu berpartisipasi } \\
\text { dalam perencanaan terkait }\end{array}$ & 23 & 69 & & 5 & 3 \\
\hline 3 & $\begin{array}{l}\text { Masyarakat perlu bekerja sama } \\
\text { dan terlibat dengan pihak-pihak } \\
\text { terkait dalam pengembangan dan }\end{array}$ & 11 & 84 & & 2 & 3 \\
\hline 4 & $\begin{array}{l}\text { Masyarakat perlu terlibat dalam } \\
\text { kegiatan-kegiatan yang berkaitan } \\
\text { dengan upaya konservasi }\end{array}$ & 15 & 82 & & & 3 \\
\hline
\end{tabular}

Ket: data disajikan dalam bentuk persentase (\%)

Berdasarkan tabel kuisioner diatas menunjukkan bahwa secara umum masyarakat sekitar kawasan wisata hutan mangrove sangat mendukung keberadaan tempat wisata tersebut. Hal ini dapat dilihat dari tingginya angka partisipasi masyarakat khususnya dalam point 1 dan 4, yaitu: Masyarakat perlu mendukung inisiatif pengelolaan pariwisata berkelanjutan dan Masyarakat perlu terlibat dalam kegiatan-kegiatan yang berkaitan dengan upaya konservasi lingkungan objek wisata maupun sekitarnya. Namun terdapat pula beberapa responden yang menjawab kurang setuju dan tidak setuju, pada point 2,3 dan 4. Hal ini disebabkan karena responden menganggap bahwa urusan perencanaan, kerjasama, maupun konservasi lingkungan 
harus dilakukan oleh pihak pengelola maupun

pemerintah kota setempat.

Tabel 3.2. Penyediaan Usaha Ekonomi Lokal pada Sektor Wisata Hutan Mangrove

\begin{tabular}{|c|l|c|c|}
\hline 1. & Keberadaan Objek Wisata ini telah & 95 & 5 \\
\hline 2. & $\begin{array}{l}\text { Keberadaan Objek Wisata Hutan Mangrove } \\
\text { Kota Langsa meningkatkan peluang usaha } \\
\text { untuk penduduk setempat maupun }\end{array}$ & 87 & 13 \\
\hline 3. & $\begin{array}{l}\text { Keberadaan Objek Wisata Hutan Mangrove } \\
\text { Kota Langsa telah meningkatkan }\end{array}$ & 60 & 40 \\
\hline 4. & Ada peningkatan ketrampilan & 83 & 7 \\
\hline
\end{tabular}

Ket: data disajikan dalam bentuk persentase (\%)

Tabel 3.3. Perolehan Manfaat Ekonomi pada Wisata Hutan Mangrove

\begin{tabular}{|c|l|c|c|}
\hline 1 & $\begin{array}{l}\text { Kegiatan wisata Hutan Mangrove Kota Langsa } \\
\text { telah meningkatkan nilai jual barang dan jasa }\end{array}$ & 89 & 11 \\
\hline 2 & Apakah ada peningkatan kehidupan & 89 & 11 \\
\hline 3 & Apakah keberadaan pengunjung & 92 & 8 \\
\hline
\end{tabular}

Ket: data disajikan dalam bentuk persentase (\%)

Secara umum keberadaan kawasan wisata mangrove ini telah meningkatkan nilai jual barang dan jasa yang dihasilkan oleh masyarakat sehingga mengarah kepada meningkatnya pendapatan rumah tangga masyarakat pesisir. Peningkatan nilai jual semakin tinggi ketika wisatawan luar daerah berkunjung ke tempat tersebut dalam jumlah yang besar. Dalam hal ini, masyarakat masih mengharapkan agar pihak pengelola maupun pemerintah daerah pada bidang terkait dapat meningkatkan promosi dan fasilitas didalam kawasan wisata untuk meningkatkan jumlah pengunjung.

Penelitian yang sama juga dilakukan di kawasan wisata Taman Hutan Kota di Paya
Bujok Seuleumak. Sebelum dan sesudah kegiatan berlangsung, tim peneliti juga melakukan pengukuran pemahaman masyarakat melalui penarikan sampling dengan kuisioner. Pertanyaan yang kami buat berkaitan dengan pengetahuan dan fungsi dari tumbuhan. Sebelum kami melakukan sosialisasi dan kegiatan ini, pemahaman masyarakat tentang ekosistem hutan dan keberadaan kawasan wisata ini masih sangat rendah. Namun setelah tim melakukan kegiatan ini, telah mampu memberi informasi dan pengaruh besar terhadap pemahaman warga tentang pentingnya keberadaan kawasan wisata. dari kuisioner yang tim sebarkan, hasilnya menunjukkan bahwa terjadi peningkatan kemanfaatan serta peningkatan kualitas hidup masyarakat sekitar ke depan.

Tabel 3.4. Dukungan masyarakat di sekitar kawasan wisata Taman Hutan Kota

\begin{tabular}{|l|l|l|l|l|l|l|}
\hline No & Pertanyaan & Sangat & & & Kurang & Tidak \\
\hline
\end{tabular}




\begin{tabular}{|c|l|c|c|c|c|c|}
\hline 1 & Masyarakat perlu mendukung & 9 & 91 & & & \\
\hline 2 & Masyarakat perlu berpartisipasi & 92 & 8 & & & \\
\hline 3 & Masyarakat perlu bekerja sama & & & & & \\
4 & Masyarakat perlu terlibat dalam & 56 & 4 & & \\
\hline
\end{tabular}

Ket: data disajikan dalam bentuk persentase (\%)

Dalam tabel diatas menunjukkan bahwa tingkat dukungan masyarakat terhadap hadirnya tempat wisata Taman Hutan Kota ini sangatlah tinggi, khususnya pada point 2 yaitu: Masyarakat perlu berpartisipasi dalam perencanaan terkait pembangunan pariwisata berkelanjutan. Hal ini disebabkan oleh keberadaan taman hutan kota ini yang berada sangat dekat dengan pemukiman masyarakat.
Sehingga mereka cenderung ingin dilibatkan dalam perencanaan pengembangan tempat wisata ini kedepannya. Sebagaimana yang terjadi pada masyarakat disekitaran tempat wisata hutan mangrove, beberapa penduduk disekitar taman hutan kota juga menganggap bahwa hal-hal yang terkait dengan kerjasama dengan pihak pengembang, dll adalah harus dilakukan oleh pihak pengelola maupun pemerintah daerah.

Tabel 3.5. Penyediaan Usaha Ekonomi Lokal pada Tempat Wisata Hutan Kota

\begin{tabular}{|c|l|c|c|}
\hline & & & \\
\hline 1 & Keberadaan objek Wisata ini telah & 87 & 13 \\
\hline 2 & Keberadaan Objek Wisata Taman Hutan & 91 & 9 \\
\hline 3 & Keberadaan objek Wisata Hutan & 76 & 24 \\
\hline 4 & Ada peningkatan ketrampilan & 92 & 8 \\
\hline
\end{tabular}

Ket: data disajikan dalam bentuk persentase (\%)

Keberadaan hutan kota telah mampu meningkatkan kesempatan kerja bagi masyarakat. Sekitar 87\% responden menjawab bahwa keberadaan tempat wisata ini telah mampu menyerap tenaga kerja, dengan peningkatan peluang usaha sebesar 91\%. Hal ini sesuai dengan kondisi di lapangan bahwasannya para pengelola tempat wisata maupun petugas parkir umumnya berasal dari masyarakat setempat. Demikian pula halnya dengan adanya tempat wisata ini telah menciptakan terbukanya peluang usaha bagi masyarakat sekitar maupun masyarakat dari luar gampong untuk menjajakan dagangannya dikantin-kantin, maupun usaha penyewaan tikar bagi para pengunjung. Penghasilan tambahan lainnya juga diperoleh masyarakat melalui jasa penyewaan bebek dayung maupun permainan mobil-mobilan untuk anak-anak. Berdasarkan hasil wawancara diperoleh keterangan bahwa jumlah pengunjung ke 
kawasan wisata ini terus menunjukkan peningkatan dari tahun ke tahun, kecuali di bulan ramadhan dan musim hujan biasanya jumlah pengunjung sedikit berkurang.

Tabel 3.6. Perolehan Manfaat Ekonomi pada Kegiatan Pariwisata Wisata Hutan

\begin{tabular}{|c|l|c|c|}
\hline & & & \\
\hline 1 & $\begin{array}{l}\text { Kegiatan wisata Taman Hutan Kota Langsa } \\
\text { telah meningkatkan nilai jual barang dan jasa }\end{array}$ & 90 & 10 \\
\hline 2 & Apakah ada peningkatan kehidupan & 90 & 10 \\
\hline 3 & Apakah keberadaan pengunjung & 95 & 5 \\
\hline
\end{tabular}

Ket: data disajikan dalam bentuk persentase (\%)

Hasil pengisian kuisioner diatas menunjukkan bahwa secara umum keberadaan kawasan wisata hutan kota ini telah memberikan keuntungan ekonomi bagi masyarakat khususnya yang melakukan aktifitas dagang dan jasa didalam kawasan wisata ini. Para responden juga memberikan informasi bahwa peningkatan jumlah pengunjung juga mempengaruhi tingkat penjualan mereka, sehingga mengarah kepada

\section{PEMBAHASAN}

\section{Partisipasi Masyarakat}

Meskipun masyarakat di gampong Kuala Langsa, kecamatan Langsa Barat mempunyai beragam mata pencaharian seperti: nelayan, pembudidaya, pegawai negeri, guru, bidan, pedagang, wiraswasta, dll, namun dari pengamatan yang dilakukan, didapatkan data bahwa mata pencaharian pokok sebagian besar masyarakat adalah sebagai nelayan dan petambak/ pembudidaya. Masyarakat yang bekerja sebagai nelayan terdiri dari 2 kelompok, yaitu kelompok masyarakat yang melakukan kegiatan penangkapan ikan di laut dengan perahu/kapal penangkapan ikan dan kelompok masyarakat melakukan kegiatan pencarian ikan di kawasan ekosistem mangrove. Sedangkan pembudidaya terbagi dalam beberapa kluster seperti: kluster budidaya udang, kluster budidaya ikan bandeng, kerapu, keramba statis, keramba jaring apung, dll.

Upaya pemanfaatan sumberdaya hayati ekosistem mangrove sudah dilakukan sejak dulu oleh masyarakat di Kuala Langsa. Pada awalnya intensitas pemanfaatan sumberdaya hayati ekosistem mangrove cukup tinggi dan tekanan terhadap kondisi ekosistem mangrove juga cukup besar karena rendahnya meningkatnya pendapatan rumah tangga mereka. Peningkatan nilai jual semakin tinggi ketika wisatawan luar daerah berkunjung ke tempat tersebut dalam jumlah yang besar. Dalam hal ini, masyarakat masih mengharapkan agar pihak pengelola maupun pemerintah daerah pada bidang terkait dapat meningkatkan promosi dan fasilitas didalam kawasan wisata untuk meningkatkan jumlah pengunjung kedepannya.

pengetahuan masyarakat dan juga kecilnya tingkat kepedulian pemerintah terhadap pengelolaan sumberdaya wilayah pesisir dan pantai. Semenjak adanya Departemen Kelautan dan Perikanan Republik Indonesia (sekarang Kementerian Kelautan dan Perikanan) dan terbentuknya Kota Langsa sebagai daerah otonom yang baru pada Tahun 2011, tekanan terhadap kondisi ekosistem mangrove mulai berkurang. Kebijakan pemerintah yang menggulirkan ketentuan pemanfaatan dan pengelolaan sumberdaya wilayah pesisir secara terpadu dan berkelanjutan, dan pada Tahun 2015 Pemerintah Kota Langsa membuat Surat Edaran Walikota Langsa yang melarang penebangan hutan pantai, secara signifikan dapat menghindari dan mengurangi degradasi kondisi ekosistem mangrove di kawasan mangrove Langsa Barat. Bahkan saat ini Pemerintah Kecamatan melalui kesepakatan bersama menetapkan pelarangan penebangan mangrove sebagai kearifan lokal yang harus dipertahankan.

Pemahaman masyarakat akan pentingnya keberadaan ekosistem mangrove semakin besar sejak Provinsi Aceh khususnya Kota Langsa dilanda gempa bumi yang berkekuatan 7,9 SR pada Tahun 2004 dengan isu adanya bencana tsunami. Pemerintah Pusat melalui Departemen Kelautan dan Perikanan bekerjasama dengan Dinas Pertanian, Perikanan dan Kelautan Kota Langsa 
melakukan pendekatan dan penyuluhan secara menyeluruh terhadap komunitas masyarakat yang bermukim di wilayah pesisir pantai untuk menjaga kelestarian ekosistem mangrove dan hutan pantai sebagai upaya penanggulangan bencana alam tsunami.

Sejalan dengan perkembangan yang terjadi di tempat wisata hutan mangrove, kondisi kawasan taman wisata kota langsa yang terdapat di Paya bujok seuleumak juga terus mengalami peningkatan jumlah pengunjung. Berdasarkan hasil pengamatan diperoleh data bahwasannya pengunjung ke tempat wisata ini terlihat meningkat signifikan jika dibandingkan tahun 2017 dengan tahun 2018 dan 2019. Sebagai contoh, pada bulan Juni 2017, jumlah pengunjung ke taman wisata kota langsa adalah 72.363 pengunjung terlihat meningkat pada tahun 2018 sejumlah 94.635 pengunjung, namun jumlah ini sedikit menurun kembali pada tahun 2019 yang hanya mencatat 87.368 pengunjung. Hal ini diprediksi karena sebagian wisatawan telah menghabiskan waktunya di kawasan wisata hutan mangrove. Oleh karena itu, diharapkan kepada pengelola kawasan wisata ini dapat terus meningkatkan fasilitas dan pelayanan demi kenyamanan pengunjung termasuk penyediaan tempat duduk atau tempat istarahat di sekitaran jalan setapak, khususnya bagi para pengunjung dari kalangan lansia, ibu hamil dan anak-anak. Tujuannya agar mereka dapat beristirahat sejenak dimanapun mereka merasa kelelahan. Penyediaan sewa tikar atau sejenisnya terlihat kurang efektif disebabkan karena pengunjung harus mengeluarkan biaya ekstra untuk menyewa tikar-tikar tersebut.

\section{Nilai Manfaat Keberadaan}

Dari seluruh karateristik performa hutan mangrove seperti Keaslian (Originality), Keunikan /Kekhasan (Uniquiness), Laju Kepunahan (Rate of Exhaustion), Keberadaan/Keutuhan Ekosistem (Ecosystem Integrity), Keutuhan Kawasan (Intactness), Keindahan Alam (Natural Beauty), Kenyamanan Alam (Natural Amenities), Tekanan Penduduk (Population Pressure) dan Aspirasi Masyarakat (Community Aspiration), hanya beberapa karaterisitik saja yang akan dianalisa dan dibahas dalam kajian ini. Karateristik performa hutan mangrove di Langsa yang dinilai antara lain adalah Keaslian (Originality), Keindahan Alam (Natural Beauty), Kenyamanan Alam (Natural Amenities), dan Aspirasi Masyarakat (Community Aspiration).

Dengan menggunakan rumus nilai keaslian, maka Originality hutan mangrove di
Langsa adalah sebagai berikut: or $=\{1$ $(300 / 1.000\} \times 100 \%=70 \%$, berarti ekositem hutan mangrove di Langsa Barat kondisinya lebih dari asli.

Demikian pula hal nya dengan kawasan wisata Taman Hutan Kota. Dari 49 hektar total kawasan, hingga saat ini lahan yang sudah difungsikan seluas 16 hektar. Or $=\{1-(16 / 49\}$ x $100 \%=67 \%$, berarti ekositem Taman hutan kota Langsa masih tergolong lebih dari asli.

Dengan menggunakan rumus : $\mathrm{Ka}=$ (Ers/Ero) x $100 \%$, dimana : $\mathrm{Ka}=$ nilai keindahan alam dalam \%; Ers = jumlah responden yang sepakat mengatakan indah, dan Ero = jumlah seluruh responden (Dirjen Pesisir dan Pulau-Pulau Kecil, 2002), maka didapat nilai keindahannya adalah sebagai berikut : $\mathrm{Ka}=(37 / 50) \times 100 \%=74 \%$, dan nilai tersebut menyatakan bahwa hutan mangrove adalah lebih dari indah. Demikian pula hal nya dengan kawasan wisata Taman Hutan Kota. Dari 50 responden, 39 orang diantaranya memilih indah. Sehingga diperoleh nilai keindahannya adalah sebagai berikut : Ka $=(39 / 50) \times 100 \%=78 \%$, dan nilai tersebut menyatakan bahwa taman hutan kota adalah lebih dari indah.

Pemanfaatan hutan mangrove sebagai lokasi wisata harus didukung oleh pemerintah daerah untuk penyediaan berbagai fasilitas yang dibutuhkan. Sebagaimana pendapat Muraleedharan et al (2009), bahwa kawasan ekosistem mangrove mungkin saja digunakan sebagai tempat rekreasi dan wisata. Lokasi wisata ini akan lebih nyaman jika didukung oleh infrastruktur yang memadai atau dimana disana potensial untuk dikembangkan infrastruktur yang cukup. Adapun pengelolaan obyek wisata dapat diserahkan kepada Desa yang berdekatan atau dikelola oleh pihak swasta.

Demikian pula halnya dengan kawasan taman hutan kota. Potensi pemanfaatan lahan tidak produktif sebagai lokasi wisata cukup besar, karena beberapa faktor pendukung seperti: Lokasi taman hutan kota, tersedianya tumbuhan yang sudah berusia ratusan tahun, dan sudah tersedianya sarana dan prasarana yang memadai seperti: jalan, jembatan yang memudahkan akses transportasi.

Dengan hadirnya kedua tempat wisata tersebut diharapkan akan berpengaruh signifikan terhadap penyerapan tenaga kerja, peningkatan pendapatan masyarakat sekitar, perputaran ekonomi daerah dan peningkatan pendapatan asli daerah kota Langsa. 


\section{KESIMPULAN}

Berdasarkan kajian yang telah dilakukan maka dapat disimpulkan bahwa:

Struktur perekonomian Kota Langsa didominasi oleh kategori perdagangan, jasa dan pariwisata sejak tersedianya kawasan wisata seperti: kawasan wisata Taman Hutan Kota di Gampong Paya Bujok Seuleumak dan kawasan wisata Hutan Mangrove di Gampong Kuala Langsa. Kategori ini memberikan kontribusi sebesar 26,34\% sejak tahun 2010 dan kontribusinya terus meningkat hingga menjadi $29,62 \%$ pada tahun 2016 dan $30,17 \%$ di tahun 2018.

Sektor kepariwisataan terlihat terus bergeliat dalam memacu pertumbuhan ekonomi di Kota Langsa. Laju pertumbuhan ekonomi pada sektor ini terus meningkat dari tahun sebelumnya. Hal itu dipengaruhi oleh bertambahnya jumlah wisatawan lokal, luar daerah maupun wisatawan internasional yang berkunjung ke sejumlah destinasi wisata yang ada di Kota ini.

Berdasarkan pengamatan di lokasi penelitian, diversifikasi usaha pariwisata dalam bentuk pengembangan tempat wisata dan

\section{DAFTAR PUSTAKA}

Adler PA. dan Adler P. 1994. Observational Techniques. In Denzin N.K. dan Lincoln Y. S. (Eds.), Handbook of Qualitative Research. Thousand Oaks: Sage Pubications.

Anselm S dan Juliet C. 1997. Dasar-Dasar Penelitian Kualitatif Prosedur, Tehnik dan Teori. Bina Ilmu Offset. Surabaya.

Ayob , M.Z., Saman, F.M., Hussin, Z., Jusoff, K. 2009. Tourist's satisfaction on Kilim River mangrove forest ecotourism service. International Journal of Bussiness and Management 4 (7) : 76-84.

Badan Pusat Statistik (BPS). 2019. Langsa Dalam Angka 2019.

Bahar, A. (2004). Kajian kesesuaian dan daya dukung ekosistem mangrove untuk pengembangan ekowisata di Gugus Pulau Tanakeke Kabupaten Takalar, Sulawesi Selatan. Tesis. Bogor : Sekolah Pascasarjana Institut Pertanian Bogor.

Barney G, Glaser dan Anselm LS. 1985. Penemuan Teori Grounded; Beberapa Strategi Penelitian Kualitatif. Usaha Nasional. Surabaya. wahana permainan telah menyediakan lapangan pekerjaan bagi masyarakat sekitar, baik sebagai petugas/ karyawan dan penjaga parkir di tempat wisata maupun sebagai penjaja kuliner, jasa penyewaan pakaian, jasa penyewaan tikar, fasilitas foto selfie dan wahana permainan, dll. Hal ini tentunya memberikan dampak positif terhadap semakin tingginya pemasukan ekonomi sekaligus memperkecil tingkat pengangguran masyarakat Langsa.

Keberhasilan pengelolaan kawasan wisata mangrove dapat dioptimalkan melalui strategi pengelolaan hutan mangrove berbasis masyarakat yang mengandung arti bahwa ada keterlibatan langsung masyarakat sekitar dalam mengelola sumber daya alam disekitar tempat tinggalnya. Mengelola disini bermaksud, masyarakat ikut memikirkan, merencanakan, memonitor dan mengevaluasi sumber daya mangrove dan manfaatnya secara berkelanjutan dengan memperhatikan kelestarian ekosistemnya. Pada dasarnya pengelolaan kawasan hutan mangrove dilakukan bukan saja difokuskan kepada kegiatan fisik tetapi kegiatan manusia sekitar yang berkaitan langsung dengan keberadaan mangrove sebagai tempat wisata.

Dahuri R. 2013. Pengelolaan Sumberdaya Pesisirdan Lautan Secara Terpadu. Balai Pustaka. Jakarta Timur.

Denzin dan Lincoln. 1994. The SAGE Handbook of Qualitative Research. Dikutip oleh John WC (2013, hlm 58. Edisi ke-3, cet. 1) dalam buku yang berjudul Penelitian Kualitatif dan Desain Penelitian Riset. Pustaka Pelajar. Yogyakarta.

Departemen Kelautan dan Perikanan, Direktorat Bina Pesisir. 2007. Pedoman Umum Pengelolaan Ekosistem Mangrove. Departemen Kelautan dan Perikanan, Direktorat Jenderal Kelautan, Pesisir dan Pulau-Pulau Kecil Direktorat Bina Pesisir. Jakarta

Dirjen Pesisir dan Pulau-Pulau Kecil, 2002. Modul Sosialisasi dan Orientasi Penataan Ruang Laut, Pesisir dan Pulau-Pulau Kecil. Departemen Kelautan dan Perikanan, Jakarta.

Edward JK dan Tallbot. 1994. Enhanced Coagulation: US Requirements and a Broader View. Water Science and Technology, 40(9), 77.

Glaser BG. 1992. Basic of Grounded Theory Analysis. Mill Valley, CA: Sociology Press. 
Kustanti A. 2011. Manajemen Hutan Mangrove. InstitutPertanian Bogor. Bogor

Lincoln, Yvonna S \&Egon G. Guba. 1985. Naturalistic Inquiry. California: Sage.

McMillan, James H dan Sally S. 2003. Research in Education. Pearson. New Jersey.

Mitchell B, Setiawan dan DH Rahmi, 2003. Pengelolaan Sumberdaya dan Lingkungan. Cetakan Kedua. Gajah Mada University Press, Yogyakarta. 498 hal.

Muraleedharan PK, K swarupanandan dan V Anitha. 2009. The Conservation of Mangroves in Kerala : Economic and Ecological Linkages. Final Report of the Project KFRI/487/05, april 2005-March 2008. Kerala Forest Research Institute, Peechi-680 653, Kerala. 47 p.

Qanun Kota Langsa No. 12 Tahun 2013 tentang rencana tata ruang wilayah (RTRW) tahun 2012-2032.

Syahid, Ahmad R. 2015. Studi Pariwisata: Pusat Referensi Ilmu Pariwisata. Diakses pada: 22 November 2019.

Undang-Undang Republik Indonesia nomor 3 Tahun 2001 Tentang Pembentukan Kota Langsa. 